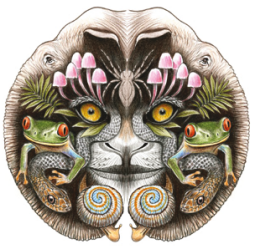

ISSN 0974-7907 (Online) ISSN 0974-7893 (Print)

OPEN ACCESS

\title{
A NEW SPECIES OF GENUS THOMISUS WALCKENAER, 1805 (ARANEAE: THOMISIDAE) FROM TELANGANA, INDIA AND A DETAILED DESCRIPTION OF THOMISUS PROJECTUS TIKADER, 1960
}

\section{G.B. Pravalikha ${ }^{1} \&$ Chelmala Srinivasulu ${ }^{2}$}

${ }^{1,2}$ Natural History Museum and Wildlife Biology \& Taxonomy Lab, Department of Zoology, University, College of Science, Osmania University, Hyderabad, Telangana 500007, India ${ }^{2}$ Systematics, Ecology \& Conservation Laboratory, Zoo Outreach Organization (ZOO), 96 Kumudham Nagar, Vilankurichi Road, Coimbatore, Tamil Nadu 641035, India ${ }^{1}$ prava.gunti@gmail.com, ${ }^{2}$ hyd2masawa@gmail.com (corresponding author)

Abstract: A new species of the genus Thomisus Walckenaer, 1805 Thomisus telanganaensis is described from Telangana, India. The new species differs from its congeners based on the female genital structure. A detailed description of Thomisus projectus Tikader, 1960 is provided for lack of one, along with illustrations of female genitalia and other distinguishing characters.

Keywords: New description, Telangana, Thomisidae, Thomisus telanganaensis sp. nov., Thomisus labefactus, Thomisus projectus.

Abbreviations: AER - anterior eye row; ALE - anterior lateral eye; AME - anterior median eye; Bp - beak-like protuberances; $d$ - dorsal; Fe femur; GO - genital opening; IC - intromittent canal; Mt - metatarsus; OUNHM, Osmania University Natural History Museum; $p$ - prolateral; PER - posterior eye row; PLE - posterior lateral eye; PME - posterior median eye; Sp - spermathecae; Tib - tibia; TBL - total body length (carapace + abdomen); v - ventral.
Thomisidae Sundevall, 1833 is a speciose family comprising 174 genera and 2166 species (Platnick 2014) of spiders worldwide. Spiders of this family are commonly known as (i) crab spiders - for their body is generally slightly flattened and the legs are laterigrade, leg I \& II long and stout, outstretched, appearing and walking sideways like a crab, and (ii) flower spiders - as they are most commonly found on flowering plants, where they lie on the flowers and wait for prey. The species of this family vary in size and color. They are small to large ( $3-23 \mathrm{~mm})$, vary from bright and colorful to dull colored. They do not build webs and capture small insects by ambush. They are usually found on
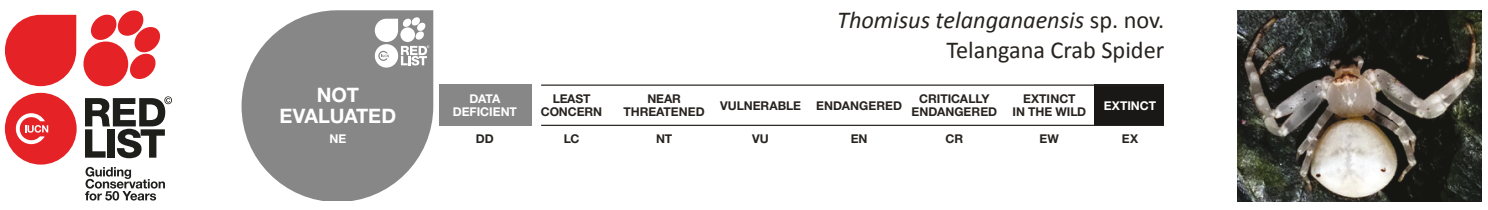

DOI: http://dx.doi.org/10.11609/JoTT.04076.7000-6 | ZooBank: urn:Isid:zoobank.org:pub:5F405274-E96E-4B5F-A7D1-FE0704979E9C

Editor: Manju Siliwal, WILD, Coimbatore, India.

Date of publication: 26 March 2015 (online \& print)

Manuscript details: Ms \# 04076 | Received 26 June 2014 | Final received 26 February 2015 | Finally accepted 01 March 2015

Citation: Pravalikha, G.B. \& C. Srinivasulu (2015). A new species of genus Thomisus Walckenaer, 1805 (Araneae: Thomisidae) from Telangana, India and a detailed description of Thomisus projectus Tikader, 1960. Journal of Threatened Taxa 7(3): 7000-7006; http://dx.doi.org/10.11609/JoTT.04076.7000-6

Copyright: (C) Pravalikha \& Srinivasulu 2015. Creative Commons Attribution 4.0 International License. JoTT allows unrestricted use of this article in any medium, reproduction and distribution by providing adequate credit to the authors and the source of publication.

Funding: The study was supported by grants from SERB, Department of Science \& Technology, Government of India and University Grants Commission, New Delhi.

Competing Interest: The authors declare no competing interests.

Acknowledgements: We thank the Head, Department of Zoology, Osmania University, Hyderabad, for providing necessary facilities and Shri. A.V. Joseph IFS, Chie Conservator of Forests (Wildlife), Andhra Pradesh Forest Department for encouragement. We acknowledge UGC, New Delhi; DST-SERB, New Delhi and UGC-DRS SAP III, Department of Zoology, Osmania University for the research grants.
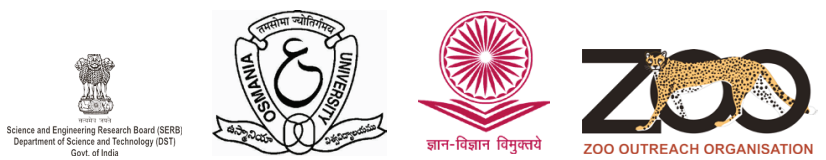
plants, shrubs, grasses, on flowering plants, also in leaf litter and sometimes under stones on the ground (Foelix 1996).

In India, the Thomisidae family is represented by 40 genera and 176 species; the genus Thomisus Walckenaer, 1805 is known by 45 species (Platnick 2014). In this paper, we describe a new species of the genus Thomisus from Telangana and provide a detailed description of Thomisus projectus Tikader, 1960 as the original description is scanty.

\section{MATERIAL AND MethodS}

Two female specimens of the new Thomisus species were collected opportunistically on 24 March 2014, in a grassland at Nagnur (18 $\left.30^{\prime} \mathrm{N} \& 79^{\circ} 9^{\prime} \mathrm{E} ; 274 \mathrm{~m}\right)$ in Karimnagar District, Telangana, India. One female specimen of Thomisus projectus was collected on 2 May 2014, in a home garden in Alwal $\left(17^{\circ} 29^{\prime} \mathrm{N}\right.$ \& 78030'E; 567m), Secunderabad in Ranga Reddy District, Telangana, India. The specimens were photographed in life, collected and preserved, and deposited in the collection of the Natural History Museum of Osmania University, Hyderabad. Line diagrams were drawn using camera lucida mounted on an Olympus binocular microscope.

All measurements presented are in millimeters. Minor colour corrections were made to the pictures. The epigynum was dissected and immersed in 50\% $\mathrm{NaOH}$ solution (following Barrion \& Litsinger 1995) for 10 minutes to study the internal structure.

\section{RESULTS}

\section{Thomisus telanganaensis sp. nov.}

(Images 1-4; Figs. 1)

urn:Isid:zoobank.org:act:AEC60C19-9C5A-4611-8BC1-7CF3D33656F7

\section{Type material}

Holotype: OUNHM.ART.ARA.2014.26, female, 24.iii.2014, Nagnur $\left(18^{\circ} 30^{\prime} \mathrm{N}\right.$ \& $\left.79^{\circ} 9^{\prime} \mathrm{E}, 274 \mathrm{~m}\right)$, Karimnagar, Telangana, India, coll. G. Chethan Kumar.

Paratype: OUNHM.ART.ARA.2014.27, female, same information as in holotype.

\section{Diagnosis}

The species is diagnosed by the presence of beak-like protuberances on the spermathecae and the diverging, loop-like intromittent canals.

Thomisus telanganaensis sp. nov. shows similarity to Thomisus labefactus Karsch, 1881 and Thomisus nirmali Saha \& Raychaudhuri, 2007 in basic epigynum structure, in having a pair of balloon-like spermathecae, but differs with respect to beak-like protuberances on spermathecae and the intromittent canal structure, respectively.

\section{Description of female}

Holotype (OU.NHM.ART.ARA.2014.26, Image 1A, 2AC, 4A-B).

Habitus: Medium-sized (TBL 6.02mm). General color: Cephalothorax off-white (Image IA), ocular area white, yellow patches present between AME-ALE (Image 2C), three narrow white bands extending from PER to the center of the carapace; sternum, chelicerae, maxillae, labium with white mottling. Legs off-white with white

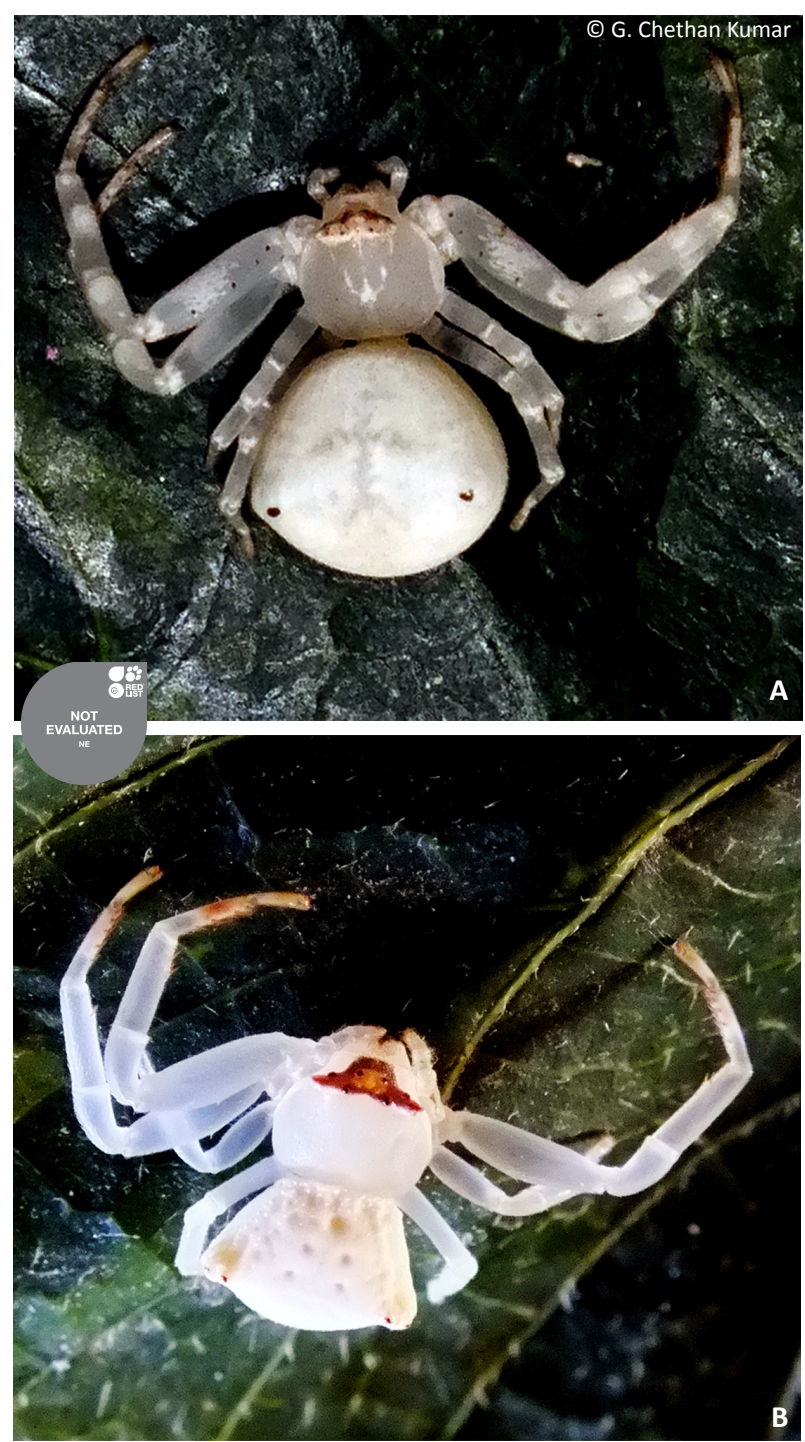

Image 1. Thomisus telanganaensis sp. nov. A - holotype; B paratype depicting morphological variations. 


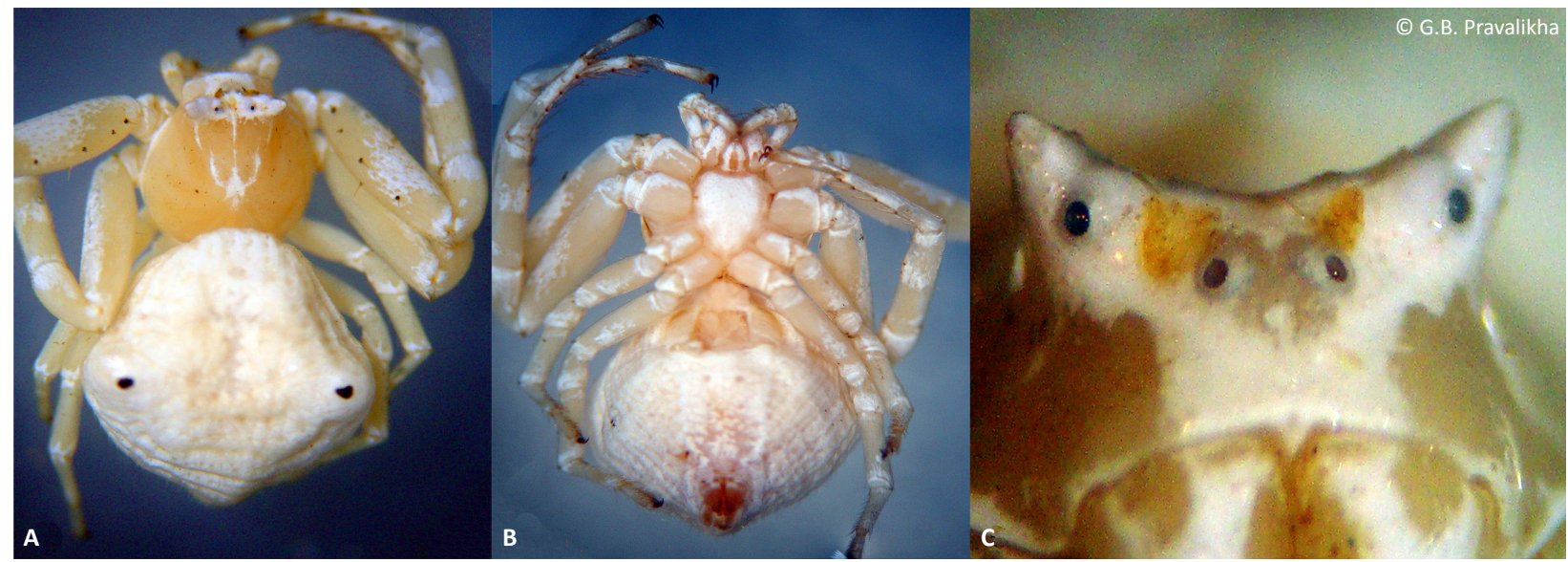

Image 2. Thomisus telanganaensis sp. nov. (in alcohol). A - Holotype, dorsal view; B - ventral view; C - ocular area.

patches, distal tip brownish (Image 1A). Abdomen with a pair of tubercles, with black spots (Image 1A, 2A).

Carapace: Rounded, wider than long, 2.27 long, 2.41 wide; chelicerae small, 0.58 long. Maxilla, longer than wide 0.53 long, 0.24 wide; labium, longer than wide 0.32 long, 0.20 wide; sternum, longer than wide 1.07 long, 0.82 wide.

Eyes: Eight eyes arranged in two rows. ALE and PLE separated by tubercles. Eyes sub equal in size, lateral eyes larger than median eyes, ALE largest, AME smallest, AMEs paler.

Legs: Leg I, II long and stout leg, III smallest.Spines present only on leg I, II. Leg formula, 1243. Lengths of legs and palp [total length (femur + patella + tibia + metatarsus + tarsus $)$ : I = $8.85(2.82+1.30+1.91+1.64+1.18) ; \quad I=$ $8.38(2.54+1.15+1.94+1.64+1.11) ; \quad I I I=3.92(1.35+0.68$ $+0.84+0.66+0.39) ;$ IV = $4.7(1.61+0.59+0.98+0.89+0.63)$; palp [total length (femur + patella + tibia + tarsus $)]=$
1.69 (0.53+0.31+0.35+0.50).Leg spination: I (Fe 4p; Tib 3,2v; Mt 5,4v); II (Tib 1,1v; Mt 5,4).

Abdomen: Wider than long 3.75 long, 4.04 wide. Pentagonal, slightly overlapping the posterior region of cephalothorax, broadest posteriorly, a pair of tubercles marked with a black spot, five sigillae present medially, four arranged in two pairs, posterior half with transverse muscular corrugations. Venter chalk white with muscular corrugation, three pairs of sigillae medially.

Epigynum (Image 4A-B; Fig. 1A-B): Without sclerotized plate, a pair of deflated balloon-like spermathecae, with beak-like protuberances, intromittent canals short, winding back and going in the opposite direction of origin.

\section{Variations}

The paratype(OU.NHM.ART.ARA.2014.27) (Image 1B, $3 A-C)$, also female, was slightly bigger than the holotype

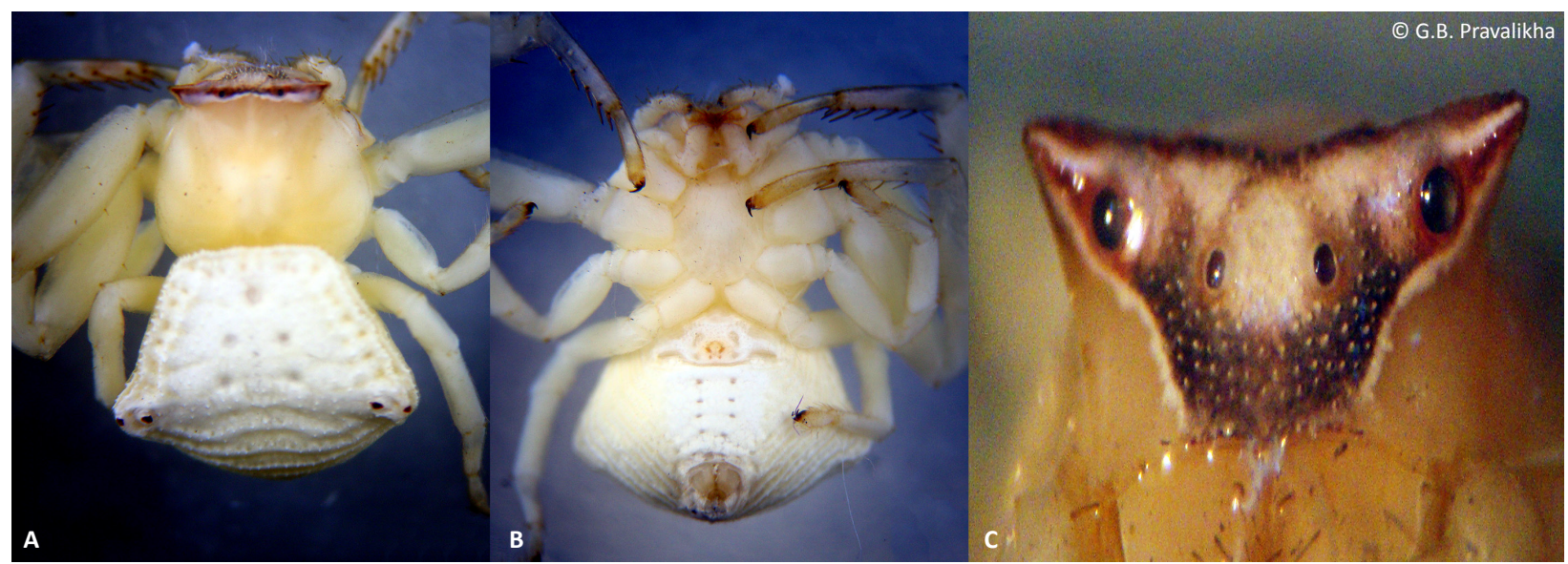

Image 3. Thomisus telanganaensis sp. nov. A - Paratype, dorsal view; B - ventral view; C - ocular area. 
Table 1. Comparison of external measurements (in $\mathrm{mm}$ ) of body parts of the holotype and paratype of Thomisus telanganaensis sp. nov.

\begin{tabular}{|c|c|c|c|}
\hline \multicolumn{2}{|l|}{ Characters } & $\begin{array}{l}\text { Holotype (OU.NHM.ART. } \\
\text { ARA.2014.26) }\end{array}$ & $\begin{array}{l}\text { Paratype (OU.NHM.ART. } \\
\text { ARA.2014.27) }\end{array}$ \\
\hline \multicolumn{2}{|l|}{ Sex } & Female & Female \\
\hline \multicolumn{2}{|l|}{ TBL } & 6.02 & 7.13 \\
\hline \multirow{2}{*}{ Carapace } & Length & 2.27 & 2.90 \\
\hline & Width & 2.41 & 3.12 \\
\hline Chelicerae & Length & 0.58 & 0.89 \\
\hline \multirow[t]{2}{*}{ Maxilla } & Length & 0.53 & 0.62 \\
\hline & Width & 0.24 & 0.34 \\
\hline \multirow{2}{*}{ Labium } & Length & 0.32 & 0.48 \\
\hline & Width & 0.20 & 0.31 \\
\hline \multirow[t]{2}{*}{ Sternum } & Length & 1.07 & 1.27 \\
\hline & Width & 0.82 & 1.07 \\
\hline \multirow{2}{*}{ Abdomen } & Length & 3.75 & 4.23 \\
\hline & Wide & 4.04 & 4.35 \\
\hline \multicolumn{4}{|c|}{ Length of legs and palp } \\
\hline \multicolumn{2}{|c|}{$\begin{array}{l}\text { Leg I [total length (femur + patella + tibia }+ \\
\text { metatarsus }+ \text { tarsus)] }\end{array}$} & $8.85(2.82+1.30+1.91+1.64+1.18)$ & $9.92(3.12+1.58+2.21+1.71+1.30)$ \\
\hline \multicolumn{2}{|c|}{$\begin{array}{l}\text { Leg II [total length (femur + patella + tibia } \\
+ \text { metatarsus + tarsus)] }\end{array}$} & $8.38(2.54+1.15+1.94+1.64+1.11)$ & $9.69(3.09+1.41+2.17+1.71+1.31)$ \\
\hline \multicolumn{2}{|c|}{$\begin{array}{l}\text { Leg III [total length (femur + patella + tibia } \\
+ \text { metatarsus + tarsus)] }\end{array}$} & $3.92(1.35+0.68+0.84+0.66+0.39)$ & $5.11(1.5+0.95+1.06+0.93+0.67)$ \\
\hline \multicolumn{2}{|c|}{$\begin{array}{l}\text { Leg IV [total length (femur + patella + tibia } \\
+ \text { metatarsus + tarsus)] }\end{array}$} & $4.7(1.61+0.59+0.98+0.89+0.63)$ & $5.7(1.81+0.92+1.2+1.01+0.76)$ \\
\hline \multicolumn{2}{|c|}{$\begin{array}{l}\text { Palp [total length (femur + patella + tibia } \\
+ \text { tarsus)] }\end{array}$} & $1.69(0.53+0.31+0.35+0.50)$ & $5.7(0.53+0.48+0.37+0.67)$ \\
\hline \multicolumn{4}{|c|}{ Leg spination } \\
\hline \multicolumn{2}{|l|}{ Leg I } & Fe 4p; Tib 3,2v; Mt 5,4v & Tib 2,3v; Mt 6,3v \\
\hline \multicolumn{2}{|l|}{ Leg II } & Tib 1,1v; Mt 5,4 & Tib 1,1v; Mt 5,4 \\
\hline
\end{tabular}

(TBL 7.13mm; Table 1). It varied from the holotype in the following characters: ocular area greyish (vs. whitish); sternum, chelicerae, maxillae, labium without white mottling (vs. with white mottling); prolateral spines on the femur absent (vs. 4 prolateral spines present) and possessing four pairs of sigillae medially on ventrum (vs. 3 pairs).

\section{Etymology}

The specific nomen is a noun in apposition taken from the name of Telangana State, India wherein the type locality is present. We propose the common English name 'Telangana Crab-spider' for this species.

\section{Distribution}

Presently known only from the type locality, Nagnur in Karimnagar $\left(18^{\circ} 30^{\prime} \mathrm{N} \& 79^{\circ} 9^{\prime} \mathrm{E}\right)$, Telangana, India.

\section{Natural History}

All the specimens were collected from the flowers of Fava bean Vicia faba L. plant.

\section{Detailed description of Thomisus projectus Tikader, 1960}

\section{Material examined}

OUNHM.ART.ARA.2014.28, female, 2.v.2014, Alwal $\left(17^{\circ} 29^{\prime} \mathrm{N} \& 78^{\circ} 30^{\prime} \mathrm{E}, 567 \mathrm{~m}\right)$, Secunderabad, Telangana, India, coll. G.B. Pravalikha.

\section{Diagnosis}

The species is diagnosed by the presence of a prominent black spot anteriorly above on the tibia of leg I and epigynum with a pair of balloon-like spermathecae connected to the genital openings. Thomisus projectus shows affinity to Thomisus dhakuriensis Tikader, 1960, Thomisus memae Sen \& Basu, 1963 and Thomisus rishus 


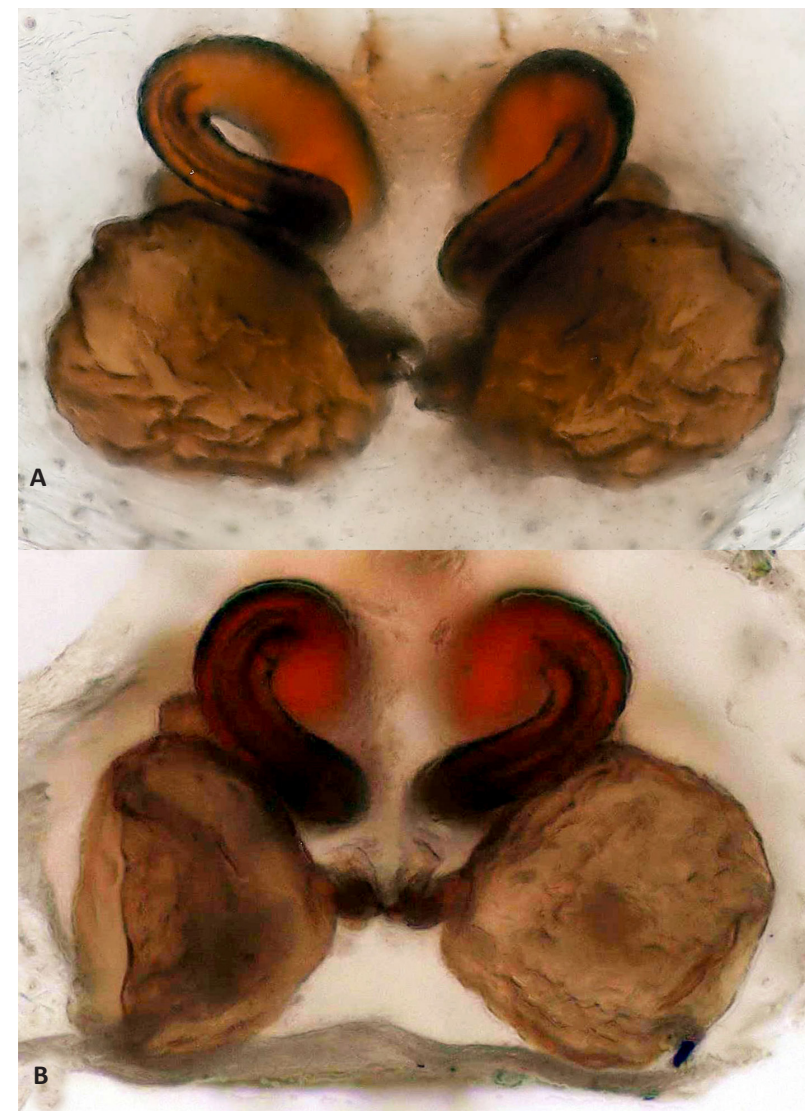

Image 4. Thomisus telanganaensis sp. nov. epigyne, dorsal view: A - Holotype; B - Paratype.

Tikader, 1970 in having black spots on first pair of legs, but differs with respect to the pattern on the abdomen and epigyne structure.

\section{Detailed description of female (Image 5)}

Habitus: Medium-sized (TBL 7.11mm). General color: Cephalothorax yellowish-brown, ocular area blackish-brown; sternum, chelicerae, maxillae, labium without white mottling. Legs pale yellow, metatarsus and tarsus of leg I \& II brown. Tibia of leg I with a black spot anteriorly above and a small black spot posteriorly; femur of leg II with a small black spot posteriorly above. Abdomen with a pair of tubercles, with black spots and antero-lateral ridges on the dorsal side, dark brown in color and appears granular.

Carapace: Rounded, wider than long, 2.96 long, 3.23 wide; chelicerae small, 1.39 long. Maxilla, longer than wide 0.75 long, 0.38 wide; labium, longer than wide 0.48 long, 0.39 wide; sternum, longer than wide 1.57 long, 1.12 wide.

Eyes: Eight eyes arranged in two rows. ALE and PLE separated by tubercles. Eyes sub equal in size, lateral
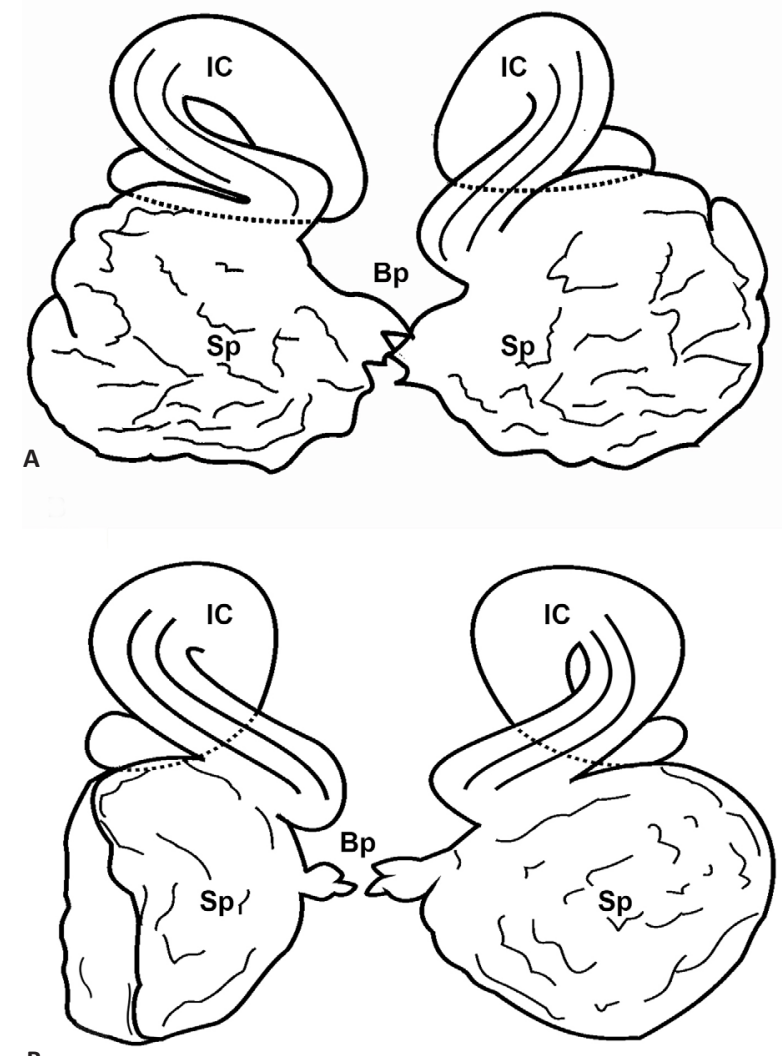

Figure 1. Thomisus telanganaensis sp. nov. epigyne, dorsal view line drawing showing deflated-balloon like spermathecae (Sp), short intromittent canal (IC), and beak-like protruberances of spermathecae (Bp). A - Holotype; B - Paratype.

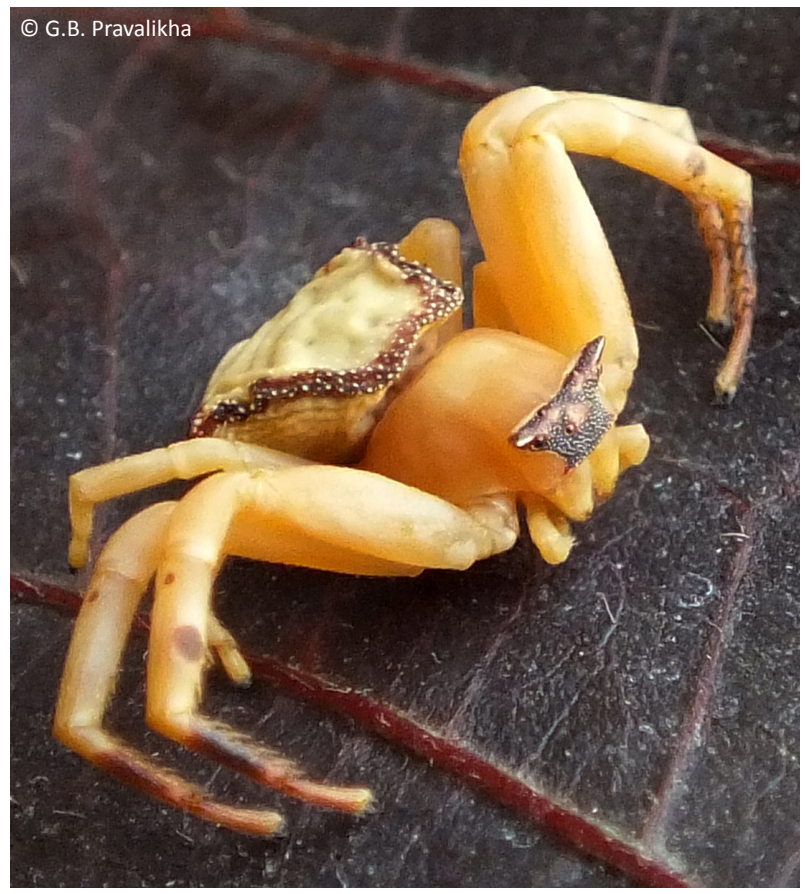

Image 5. Thomisus projectus Tikader, 1960 live habitus. 


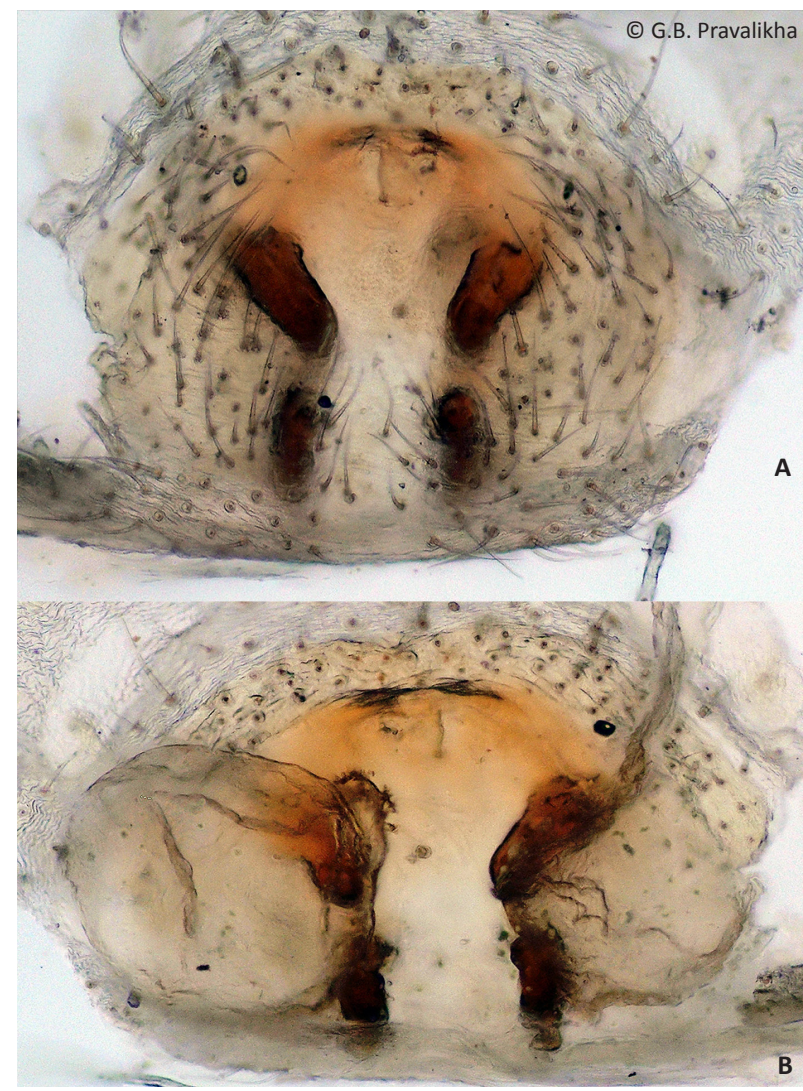

Image 6 A-B. Thomisus projectus Tikader, 1960 epigyne A - external view; B - internal view.

eyes larger than median eyes, ALE largest, AME smallest, AMEs paler.

Legs: Leg I, II long and stout; leg III, smallest. Spines present only on leg I, II. Leg formula, 2143. Lengths of legs and palp [total length (femur + patella + tibia + metatarsus + tarsus $)]: ~ I=10.89$ $(3.22+1.78+2.43+1.99+1.47) ; \|=10.91(3.45+1.64+2.40+$ $1.99+1.43) ; I I I=5.3(1.69+0.94+1.12+0.92+0.60) ; I V=6.26$ $(2.18+0.91+1.36+1.09+0.72)$; palp [total length (femur + patella + tibia + tarsus $)]=2.34(0.69+0.46+0.49+0.70)$ Leg spination: I (Tib 3,1v; Mt 6,6v); II (Tib 2,1v; Mt 6,5).

Abdomen: Wider than long 4.15 long, 4.53 wide. Pentagonal, slightly overlapping the posterior region of cephalothorax, broadest posteriorly, anterior lateral ridges dark brown with yellow spots, five sigillae present medially, four arranged in two pairs, posterior half with conspicuous transverse muscular corrugations. Venter chalk white with muscular corrugation, three pairs of sigillae medially.

Epigynum (Image 6A-B; Fig. 2A-B): Epigynum simple, without sclerotized plate, with a pair of balloonlike spermathecae, connected to the genital openings.

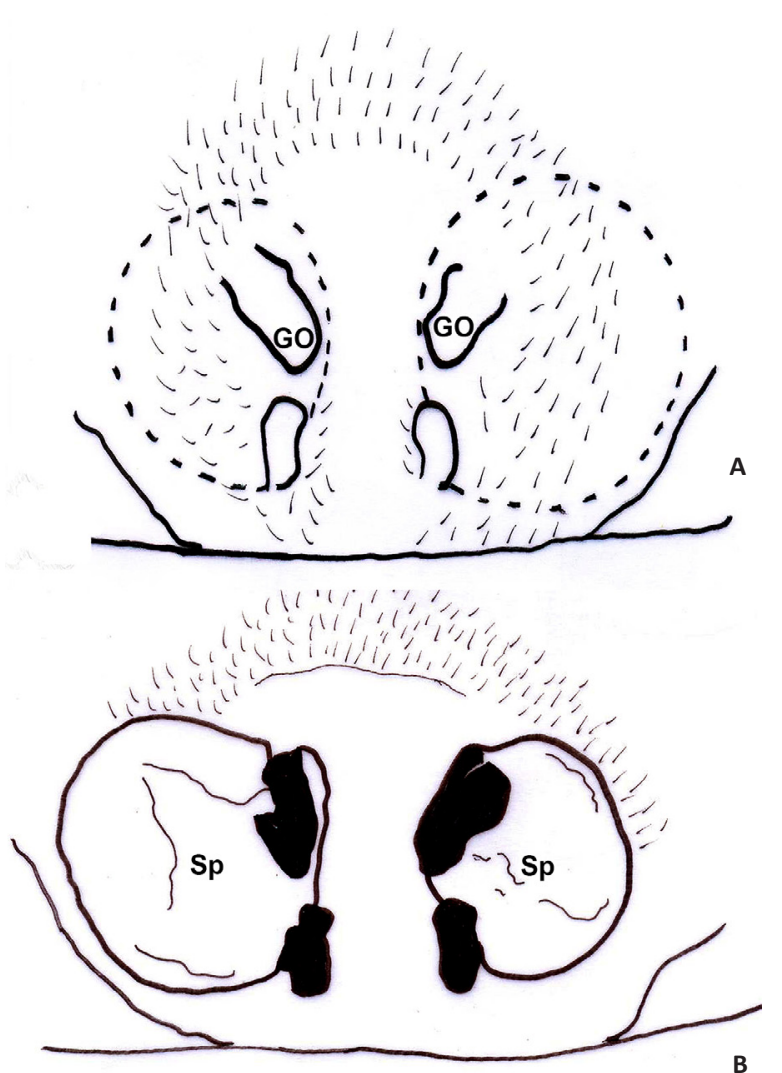

Figure 2 A-B. Thomisus projectus Tikader, 1960 epigyne, line drawing showing balloon like spermathecae $(\mathrm{Sp})$ connected to genital openings (GO). A - external view; B - internal view.

\section{Distribution}

This species is endemic to India and has been reported from West Bengal (Tikader 1960), Chhattisgarh (Gajbe 2003), Madhya Pradesh (Gajbe 2003), Assam (Chetia \& Kalita 2012), Rajasthan (Lawania et al. 2013) and Telangana (present study).

\section{Natural History}

The specimen from Secunderabad, Telangana has been collected from a home garden, on flowers of marigold Tagetes sp. The type specimen was collected from Howrah, a suburb of Kolkata (Tikader 1960).

\section{Discussion}

The two female specimens of Thomisus telanganaensis sp. nov. show variation in the morphology with respect to clypeal area, coloration, spination and abdomen pattern, giving an illusion that both are different (Images 1-3), but are identical with respect to the structure of the internal genitalia (Image 4). These kind of intraspecific variations were also noted in Thomisus labefactus Karsch, 1881 and T. okinawensis 
Strand, 1907 (Ono 1988).

Out of 45 species belonging to the genus Thomisus, 43 species are reported from mainland India, while two species (Thomisus andamanensis and T. armillatus) are restricted to Andaman \& Nicobar Islands (Platnick 2014). Thomisus nirmali Saha \& Raychaudhuri, 2007 from West Bengal was the latest species described from mainland India, indicating a possibility of presence of more diversity within this family.

No studies published so far on $T$. projectus have attempted to provide detailed description of the species (Tikader 1980; Gajbe 2003). In view of the variability with respect to external and internal epigynal structures among the morphologically similar looking individuals of spiders it would be difficult to determine the actual range of many species belonging to the genus Thomisus. Further studies from different parts of India will help in addressing the Linnaean shortfall with respect to this group of spiders.

\section{REFERENCES}

Barrion, A.T. \& J.A. Litsinger (1995). Riceland Spiders of South and Southeast Asia. CAB International, UK \& IRRI, Philippines, 716 pp.

Chetia, P. \& D.K. Kalita (2012). Diversity and distribution of spiders from Gibbon Wildlife Sanctuary, Assam, India. Indian Journal of Arachnology 1(1): 130-142.

Foelix, R. (1996). Biology of Spiders. Oxford \& Harvard University Press, London, 306pp.

Gajbe, P.U. (2003). Checklists of spiders (Arachnid: Araneae) of Madhya Pradesh and Chattisgarh. Zoo's Print Journal 18(10): 12231226; http://dx.doi.org/10.11609/JoTT.ZPJ.18.10.1223-6

Lawania, K.K., K. Trigunayat, P.S. Kain \& M.M. Trigunayat (2013). On the spider diversity in and around Deeg town, Bharatpur (Rajasthan). Indian Journal of Arachnology 2(2): 47-52.

Ono, H. (1988). A Revisional Study of the Spider Family Thomisidae (Arachnida: Araneae) of Japan. National Science Museum, Tokyo, $351 \mathrm{pp}$.

Platnick, N.I. (2014). The World Spider Catalog, Version 15.0. American Museum of Natural History. Available from: http://research.amnh. org/iz/spiders/catalog/THOMISIDAE.html (Accessed 25 June 2014).

Saha, S. \& D. Raychaudhuri (2007). New crab spider of the genus Thomisus Walckenaer from Kolkata, West Bengal. Munis, Entomology \& Zoology 2(2): 439-442.

Tikader, B.K. (1960). On some new species of spiders (Arachnida) of the family Thomisidae from India. Journal of the Bombay Natural History Society 57(1): 173-183.

Tikader, B.K. (1980). The Fauna of India. Spiders: Araneae Vol 1, Part 1. Zoological Survey of India, Calcutta, 239pp. 